\title{
Health Education in Lithuanian Primary Schools: Conceptual Ideas and Main Strategic Directions
}

\author{
D. Kalesnikienè
}

\begin{abstract}
The purpose of this article is to introduce conceptual ideas and main strategic directions of health education in Lithuanian primary schools. These conceptual ideas and strategic directions correspond not only to the vision of Lithuania, but also to the worldwide trends of health education, which are reflected in the work of the World Health Organization and European tendencies. The relevance of this problem and the qualitative study of pre-school and primary school teachers' approach to health education are discussed in the article. One of the goals of Lithuanian primary education, which is focused on the development of child's mental, physical and social education, is the assurance of successful health education of a child in primary school by contributing to one's spiritual, physical, mental and social capacity and well-being. Approach to physical, mental and social health and their interrelations in solving educational tasks that are oriented to the components of knowledge and understanding, their application, skills and attitudes, moral values are described in the article.
\end{abstract}

Index Terms - Conceptual ideas, health education, primary school, strategic directions, Lithuania.

\section{INTRODUCTION}

On the individual level health education is strongly influenced by families' and social fundamental values. In the area of health education these values are related to the field of health education policy, which should have harmony on all levels.

Health education is linked to family, school, district, municipal, national, European, global contexts. All these contexts presented in Fig. 1 from the closest to the farthest should influence the development of primary school pupils' health education, thus on all these levels health education policy is important to every person.

In the field of health education family and school should seek for more than pupils' understanding, because success in education is determined not only by understanding health as a value - properly understood health education requires formation of fundamental commitment and virtues. The closest environment, such as family, school or local community is the most important for education of primary school pupils. Nevertheless even primary school pupils together with their class or school can be involved in the project on European level or the World Health Organization level. Levels shown in Fig. 1 influence each other thus the responsibility of schools is not only to ensure that pupils recognize health and its education as a public value, but they

Manuscript received November 1, 2013; revised January 17, 2014.

D. Kalesnikiene is with Lithuanian University of Educational Sciences, Vilnius, CO 08308, Lithuania (e-mail: danguole.kalesnikiene@gmail.com). would be familiar with its scale and nature [1].

Therefore the ideas and main directions of health education in primary school should be analyzed in connection with all these levels. Another idea is the assurance of interaction of formal and informal education in order to expand the field of health education implementation in primary schools and links between formal and informal education. Health education should be seen integrally as a relevant area of primary education.

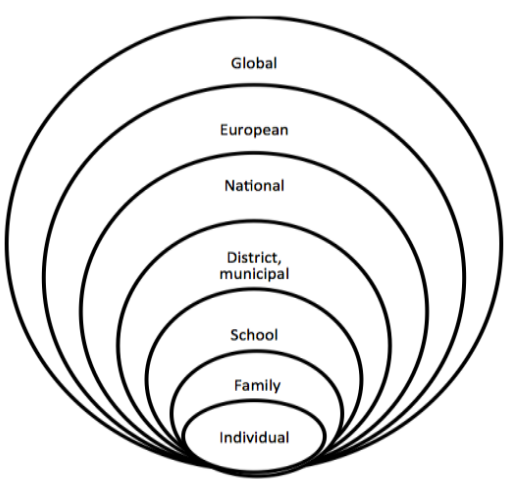

Fig. 1. Levels of health education.

\section{AsSUmPtions OF HEAlth EDUCATION}

Lithuania is a member of the World Health Organization since November 25, 1991 and along with 52 countries (total number of countries is 53) belongs to the Regional Office for Europe. It has influence to national health education policy. Together with the World Health Organization Lithuania implements various projects, the most significant of which in primary education is the "Healthy School" project (still going on). On the efforts of the World Health Organization the European Network of Health Promoting Schools was being created since 1991. In 1993 Lithuania was accepted to the European Network of Health Promoting Schools. Twelve schools of our country became real members of the Network, later other six were involved into the work of the European Network of Health Promoting Schools as associate members. Around hundred various types of Lithuanian schools are members of the national network of health promoting schools. The activities of Lithuanian network of health promoting schools are coordinated by the Coordination Bureau of the Network of Health Promoting Schools, which is set up in the State Environmental Health Centre. Schools that are implementing health promotion project had a goal to create health education structure. Since healthy and safe environment has a great impact on health education, schools had to create healthy and safe learning conditions (properly installed learning and subsidiary premises, canteens, playgrounds). 
Schools could implement health education through formal education (it was tried to integrate health education into the curriculum on different learning levels) and informal education not only by helping every pupil to realize one's physical, mental and social abilities, but also by developing their family members' need and responsibility for health, which helped to include and educate the whole community. The purpose of health education can be reached in various ways. Material and human resources should be used effectively by helping pupils and all school staff develop healthy lifestyle habits, which helps to preserve and strengthen health and healthy environment. Specific tasks for the creation of healthy and safe environment, strengthening health should be formulated for the whole school staff. While creating good emotional environment it is important to establish, maintain and strengthen good relations between pupils, pupils and teachers, as well as between school, family and society. Together with health care specialists it is necessary to develop and promote healthy lifestyle while forming wider approach to health.

Even though Lithuania is a member of the European Network of Health Promoting Schools since 1993, but these activities in Lithuania did not cover all types of schools, were not well coordinated and systemic, not fully integrated into existing structures on national and municipal levels. Therefore the government of Lithuania prepared and approved the Children's Health Promotion Program for 2008-2012, which aimed at improving children's health education, environmental health promotion, disease and injury prevention and control [2]. The Children's Health Promotion Program for 2008-2012 was prepared in order to implement Lithuanian Law on Public Health Care. It was aimed at the development of children's health promotion activities while increasing the competence of specialists working with children and mobilizing state, local authorities, school communities and social partners for health promotion activities, expanding the network of health promoting schools, spreading the experience of such activities and improving its quality. When implementing the program children's health promoting environment was being created, children's healthy lifestyle attitudes and abilities were developed, organization of primary prevention of children's diseases and injuries was being improved. Methodological recommendations for children's healthy nutrition, physical activities and prevention of risk factors of chronic non-infectious diseases were prepared for the specialists working with children. Provisions and data of the World Health Organization show that effective are only complex and multi-sectorial health promoting programs, which activities are coordinated on national, local and individual levels. This has to be taken into account when planning that the results of the Children's Health Promoting Program would be long-term and leading to the development of children's health. Another step in Lithuanian health education policy was taken in 2013. The Parliament of the Republic of Lithuania declared 2013 the Year of Health and the Government addressed the public: "the Government of the country is committed to consistently implement all provided health promotion means. Only by acting together we can give meaning to the ideas of the most important treasure-health and foster provisions of nation's healthy lifestyle. The World Health Organization says that only $10 \%$ of human health is determined by health care, $20 \%$ by heredity, $20 \%$ by environment, and $50 \%$ are determined by lifestyle. The World Health Organization has just approved new European health policy framework "Health 2020" [3]. The main aim of this framework is "health in all policies". We, the citizens of Lithuania, Europe and the world, are firmly convinced that in the XXI century health has become a priority policy area of each country" [4]. In the new health program for 2020 more emphasis will be given to cooperation with other sectors of the national economy in pursuance that the health of Lithuanian residents would become the priority of all sectors of the country. On the occasion of Lithuanian Presidency of the Council of the European Union in 2013 the aim "to practically prove that healthy Europe, healthy society is the basis of progress and prosperity and to urge European countries to unite their efforts towards health and wellness" is highlighted. Priorities of Lithuanian Presidency were chosen according to the European health policy "Health 2020" and relevant health problems of Lithuanian society as well as country's progress of improving the work of health care system in which the attention should also be paid to health education. The values of the World Health Organization's European health policy "Health 2020" are the basis of the new Lithuanian Health Program for 2011-2020.

Another assumption for consistent health education policy of Lithuania is the provisions of the Lithuania's Progress Strategy "Lithuania 2030" (see Fig. 2).

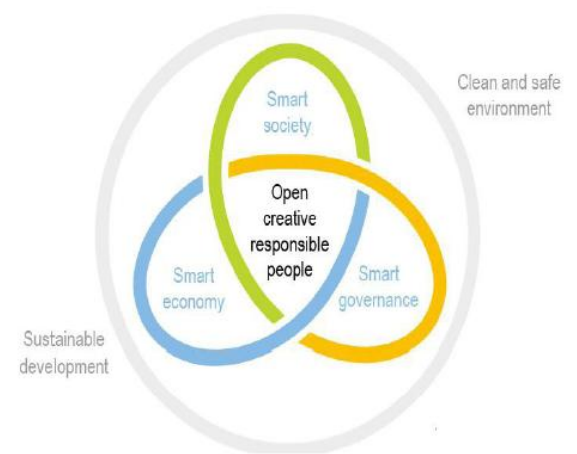

Fig. 2. Lithuania's progress strategy.

The Lithuania's Progress Strategy expresses the vision of Lithuania and has been worked out by the people who actively participated in its preparation with proposals and ideas. This document emphasizes health and its education from an early age: "Health is seen as the most valuable asset and is important for both personal and public well-being and, therefore, a healthy lifestyle is consistently fostered from young age, focusing on disease prevention and health preservation" [5].

The Strategy, emphasizing on healthy lifestyle and the importance of preventive measures through the development of society's awareness, gives meaning to its development and aims: "to develop a healthy lifestyle as a prerequisite for a dynamic society. To mobilize public and institutional efforts towards better public health through measures preventing the use of alcohol, tobacco and drugs and increased public awareness as regards the benefits of a healthy lifestyle" [5]. 
The aim of the European Union health education is oriented towards significant health improvement, well-being of the population, reducing health inequalities and ensuring health system, which activities are directed to a person. Health education is the basis for health promotion. Health education should promote the development of good habits, values and behaviors, related to health.

\section{HEALTH EDUCATION AT SCHOOL}

When planning health education activities school could provide four main directions, as shown in Fig. 3:

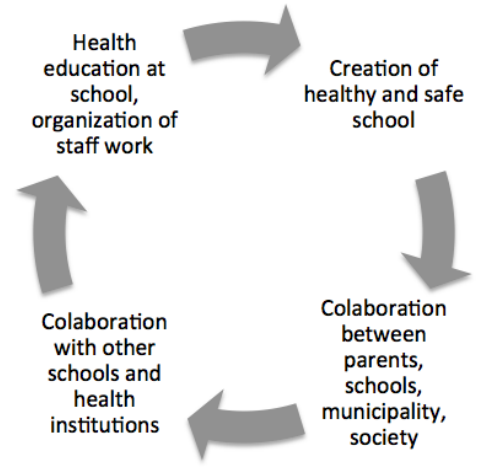

Fig. 3. Health education directions for schools.

These directions would lead to the development of coherent health promotion policy at school, which should combine both formal and informal education corresponding to the age and needs of primary school pupils. Formal education is implemented according to the General Programs of Primary and Basic Education. The Minister of Education approved the Primary and Basic Education General Programs (further - the General Programs) on 26 of August 2008 by the order No. ISAK-2433 [6]. In the General Programs health education is seen as an integral part of primary education. The General Programs are composed and oriented to the goals of key competencies, therefore the goals of health education as integral part of competencies should cover all key and special competencies as shown in Fig. 4 and should be implemented by developing these competencies.

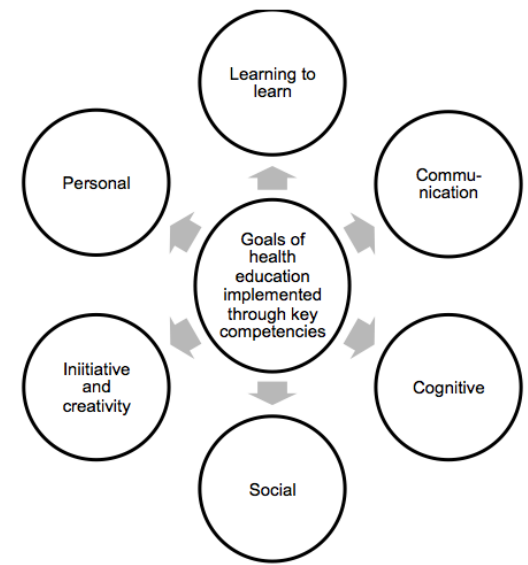

Fig. 4. Links between the goals of health education and key competencies.

The section of the Education of key competences and life skills, which includes Learning to learn, Communication, Sustainable development, Cultural awareness and Health and life skills, is distinguished in the General Programs. The links between educational fields and integrated programs are also presented in the Programs. Integrated programs had to be implemented during the lessons of all subjects, activities of school community and informal education. They are aimed at the development of key competences. But it was decided that in Lithuania health education in schools is one of the areas that needed improvement, therefore the General Health Education Program (2012) [7] was created. It sets compulsory goals and objectives of health education for all types of schools, discusses possibilities of health education implementation and educational guidelines, provides pupils' achievements and its content in schools that are implementing general education programs (see Fig. 5).

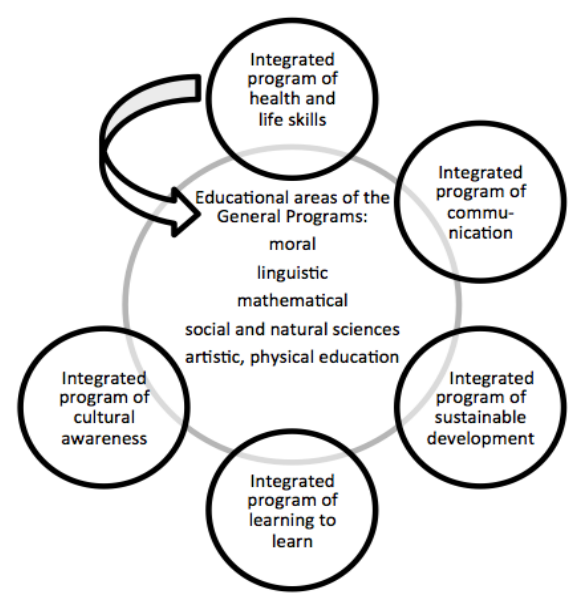

Fig. 5. The general program created for health education.

The General Health Education Program was influenced by both the initiatives of the World Health Organization, as well as political priorities provided in "Health 2020", which are oriented towards an important goal - to significantly improve health and well-being of the population, reduce health inequalities and to ensure person-oriented health system activities. The objective of health education set in the General Health Education Program is helping pupils acquire holistic health concept, developing abilities, habits and attitudes that are beneficial for health, understanding responsibility for the health of their own and others, encouragement to choose a healthy lifestyle.

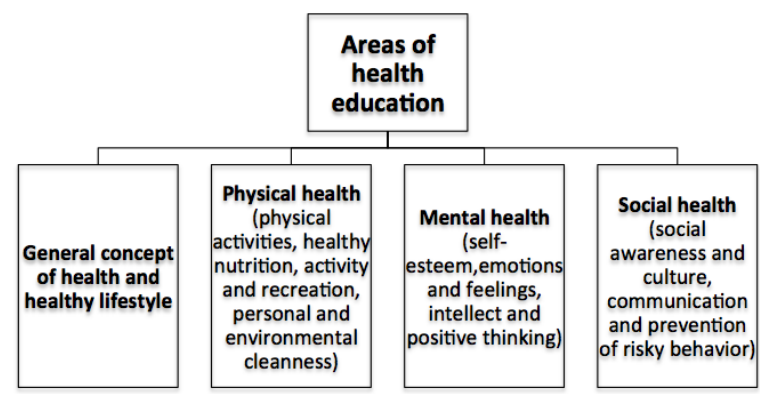

Fig. 6. The coverage of health education.

Four areas of health education, which include important physical, mental and social health education areas, as well as general concept of health and healthy lifestyle, are provided in the General Health Education Program as shown in Fig. 6.

But after analyzing the yearly plan of the Ministry of Education and Science for 2013 it can be concluded that the General Health Education Program will only be started to 
implement in schools from 2014. In addition to that, emphasis is put to preparation and implementation of purposive programs for safe school, informal educational prevention, which promote children's health and social and emotional immunity (2012-2016) [8].

Successful implementation of the General Health Education Program requires not only the creation of healthy and safe school environment, but also teachers' preparation, inclusion of other school specialists, parents and other members of society, their support. European and global dimensions help to understand the purpose and meaning of health education with the projection to the future and the approval of five main values of the European network of health promoting schools "Schools for Health in Europe": justice, support, empowerment, operational competence and democracy.

\section{APPROACH OF PRE-SCHOOL AND PRIMARY SCHOOL TEACHERS TO HEALTh EdUCATION PROBLEMS}

Qualitative study was organized in order to find out if pre-school and primary school teachers see the problems of health education. Pre-school and primary school teachers were asked to identify the biggest and the most complicated problems of health education that needed to be addressed as soon as possible. Qualitative study was being conducted from 20 August 2013 till 20 November 2013 during the meetings with teachers. 200 pre-school and 204 primary education teachers participated in the study. They had to identify the biggest problems in health education. The answers of teachers are shown in Table I.

TABLE I: THE PROBLEMS IDENTIFIED BY PRE-SCHOOL AND PRIMARY SCHOOL TEACHERS

\begin{tabular}{|c|c|}
\hline Pre-school teachers & Primary school teachers \\
\hline $\begin{array}{l}\text { Children's parents are less } \\
\text { interested in education, they are } \\
\text { asking about childcare }(60 \%)\end{array}$ & $\begin{array}{l}\text { Children are not used to } \\
\text { healthy nutrition, snack } \\
\text { unhealthy food and eat a lot of } \\
\text { sweets }(20 \%)\end{array}$ \\
\hline $\begin{array}{l}\text { Children at home are not thought } \\
\text { necessary hygiene skills ( } 50 \%)\end{array}$ & $\begin{array}{l}\text { Children at home are not } \\
\text { thought necessary hygiene } \\
\text { skills }(20 \%)\end{array}$ \\
\hline $\begin{array}{l}\text { Parents are against their children } \\
\text { being outside in winter, spring } \\
\text { and late autumn }(42 \%)\end{array}$ & $\begin{array}{l}\text { Children come to school } \\
\text { without having had breakfast } \\
(42 \%)\end{array}$ \\
\hline $\begin{array}{l}\text { Children are brought to } \\
\text { pre-school ill, not fully recovered } \\
\text { after the illness }(20 \%)\end{array}$ & $\begin{array}{l}\text { Children do not get enough } \\
\text { sleep }(20 \%)\end{array}$ \\
\hline $\begin{array}{l}\text { Children are not able to eat } \\
\text { independently }(25 \%)\end{array}$ & $\begin{array}{l}\text { Children do not have } \\
\text { communicative } \\
\text { collaboration skills }(22 \%) \\
\text { Children cannot control their } \\
\text { emotions and do not feel } \\
\text { boundaries }(15 \%)\end{array}$ \\
\hline
\end{tabular}

In conclusion it can be said that the biggest problems of health education are related to health education at home. The answers of teachers show that in pre-school age parents think that health of children should be ensured by taking care of them, making a lot of things for them, not by teaching them hygiene skills or teaching them to become and be independent. Children are brought to school ill, which endanger not only themselves, but other children as well.
Children's preparation for school is not sufficient, they lack social skills, such as communication and collaboration, and they are not thought to control their emotions or take into account other people. Children are not thought healthy lifestyle (they do not have established sleeping routine or eating rules).

The problems identified by pre-school and primary school teachers indicate the need for universal health education, which is relevant from the pre-school age. Health education should be continued in primary school. Health education, involvement and initiatives of families and society are also relevant to the solution of this problem.

\section{CONCLUSION}

1) Health education should be organized with respect to all contexts of health education: individual, family, school, local community, municipal, national, European and global, so that pupils would recognize health and its education as a public value and would be familiar with its scale and nature.

2) When seeking effective health education results school should organize health education policy in these directions: formal and informal health education at school according to pupils' age and needs, organization of the work of school staff, creation of healthy and safe school environment, cooperation between parents, school, municipality, society, cooperation with other schools in the area of health education.

3) In order to implement health education programs in schools general health and healthy lifestyle concepts should be thought already in primary schools as well as complete education should be oriented to key competences in the areas of physical health (physical activity, healthy nutrition, recreation, personal and environmental cleanness), mental health (self-esteem, emotions and feelings, intellect and positive thinking) and social health (social and cultural awareness, communication and prevention of risky behavior).

4) The success of health education in Lithuanian primary schools depends not only on the preparation to implement new programs, but also on wider context of health policy, policy of the European Union and the World Health Organization. The solution of national, European and global health education problems should become the priority area of education and health policy not only de jure, but also de facto and should be based on good experience of different countries, municipalities, schools, teachers and pupils in formal and informal education.

\section{REFERENCES}

[1] T. H. McLaughlin, Modern Philosophy of Education: Democracy, Values, Diversity, Kaunas: Technology, 1997.

[2] Children's Health Promotion Program for 2008-2012, approved by the act No. 836 of the Government of the Republic of Lithuania, August 27, 2008.

[3] Health 2020. A European policy Framework and strategy for the $21^{\text {st }}$ century. World Health Organization 2013. [Online]. pp. 1-190. Available:

http://www.euro.who.int/_data/assets/pdf_file/0011/199532/Health2 020-Long.pdf. 
[4] Appeal of the Government of the Republic of Lithuania to the public, 2013.

[5] Lithuania's Progress strategy. Lithuania 2030. [Online]. pp. 8-10. Available: http://lietuva2030.1t/images/stories/en_lietuva2030.pdf

[6] The Primary and Basic Education General Programs, Vilnius: Education Supply Center, 2008.

[7] General Health Education Program approved by the order No. V-1290 of the Minister of Education and Science, August 31, 2012.

[8] Priority Measures for the Implementation of 2012-2016 Program of the Government of the Republic of Lithuania, approved by the order No. $V-386$ of the Government of the Republic of Lithuania on 8 of May, 2013.

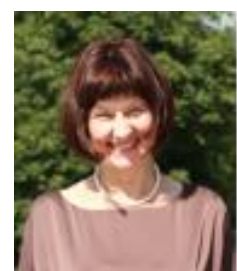

Danguolè Kalesnikienė is an associate professor of the Department of Education of Lithuanian University of Educational Sciences and the specialist of the Department of Preschool and Primary Education of the Education Development Centre.

She has published significant articles in the area of primary education, such as: Teacher's role in applying ICT in primary school. Journal of International Scientific Publication: Educational Alternatives (2013); Primary Education of Lithuania: the Discourse in the Change of Education of Lithuanian Language. Valodu apguve: problémas un perspektyva IX Liepaja (2013); The dependence of primary school pupils Lithuanian language achievements on the teacher's didactic culture. Pedagogika (2009) and etc. Domains of scientific interests are social and primary education, educational diagnostics and native language. 